\title{
TEXTUAL THEORY AND COMPLEX BELIEF SYSTEMS: TOPOLOGICAL THEORY
}

\author{
J. Nescolarde-Selva and J.L. Usó-Doménech \\ Department of Applied Mathematics. University of Alicante. Alicante. Spain.
}

\begin{abstract}
In order to establish patterns of materialization of the beliefs we are going to consider that these have defined mathematical structures. It will allow us to understand better processes of the textual, architectonic, normative, educative, etc., materialization of an ideology. The materialization is the conversion by means of certain mathematical correspondences, of an abstract set whose elements are beliefs or ideas, in an impure set whose elements are material or energetic. Text is a materialization of ideology and it is any representation of the Reality represented by symbolic means. In all text $\mathrm{T}$ we can observe diverse topological structures: Metric Textual Space, Textual Topology and a Textual Lattice.
\end{abstract}

Keywords: Beliefs, connotative significance, subtext, text, text theory, textual basis, textual function, textual topology

\section{INTRODUCTION}

A text is any representation of the Reality represented bysymbolic means. With this text definition it is included from the text written to any architectonic structure, painting, musical score, or mathematical models. A text can be from the Bible to the signal of STOP, dumb gestual signs used by deaf person or the document Braille used by blind. Therefore, the text, that we will represent by $T$, anyone is their nature, is the cultural unit par excellence. Text $\mathrm{T}$ usually hâs a name. They are anonymous Ts and collective Ts, but in general, they have as creator to an individual subject, an author $\mathrm{S}_{\mathrm{A}}$. Also, $\mathrm{T}$ has one (or infinity) interprets that, following the tradition, we will call reader $\mathrm{S}_{\mathrm{R}}$.

One of the scholars whose work in the text theory tradition has been highly productive and whose theory continues to evolve is Walter Kintsch: Construction-Integration Model (Kintsch, 1988). This will provide a specific theoretical example with which to compare our claims about the distinctive processes of literary understanding. At the linguistic leyel, stylistic properties distinctive to literary language such as phonemic or grammatical deviation must be taken into account. At the conceptual level, the local and global meanings mentioned by Kintsch must be supplemented by affective, imaginal, and personal meanings that readers bring to a literary text, prompted in part by their response to the stylistic features. Kintsch's model of text understanding was developed partly in response to problems with top-down approaches based on scripts, frames, or schemata. The general outline of an alternative to text theories has already been suggested for Kintsch (1988). However, it is useful to embed this alternative historically in literary theory and simultaneously to articulate how it contrasts with text theories. The origins of defamiliarization theory may be found in the Romantic period, especially in Coleridge's (1817/1983) proposal that the purpose of literature is to overcome the automatic nature of normal, everyday perception. Poetry thus overcomes custom, it defamiliarizes, and it restores feelings that were blunted or decayed. A similar position is presented in one of the founding documents of Russian Formalist criticism, the essay "Art as Technique" by Victor Shklovsky, published in 1917. Habitualization, said Shklovsky (1917/1965), devours life. Shklovsky and his co-workers underscored the significance of the literary device, by which was meant a range of features, many of 
them linguistic, that characterize literary texts and that initiate defamiliarization. The project of classifying these features and accounting for their effects was taken up in the following decades by the Prague Linguistic Circle, among whom the most influential members were Jakobson and Mukarovský.Spencer claimed that successful style has the effect of "economizing the reader's or the hearer's attention" and presenting ideas so "that they may be apprehended with the least possible mental effort" (Spencer, 1872). On the contrary, Shklovsky argued: the function of style in literature is to challenge familiar economies of comprehension and to enrich perception. Modern text theories are based on a postulate similar to Spencer's: that the function of style is to economize comprehension. In general, textual theories describe a resource-limited system in which cognitive structures (e.g., story grammars) or procedures (e.g., integrating processes) economize comprehension by deleting irrelevant propositions, inferring relevant propositions, and building macro-propositions. The economizing effects of these structures and procedures per se are substantiated by an impressive body of empirical studies that range from word recognition to story recall. However, whether the stylistic features of literary texts also have economizing effects is the issue that separated Shklovsky and Spencer and which separates contemporary text theory from defamiliarization theory. According to defamiliarization theory, literary texts reverse the economizing effects of story grammars, schemata, etc. Text theories and defamiliarization theory also differ in the typical discourse examples that are selected for study. In text theories, which deny special characteristics to literary texts, exemplary texts are those that present a normal sequence of narrative or expository propositions. Such texts, usually simple stories or short essays, may be understood as a complex of more-or-less coherently related propositions, The economies by which irrelevant propositions are deleted, relevant propositions inferred, and macro-propositions built, dominate theories of comprehension in this domain. On the other hand, in defamiliarization theory, where the special characteristics of literary texts are acknowledged, exemplary texts are those that present complexes of propositions using various literary devices. The meanings of these texts, such as short stories or poems, are understood only when literary devices such as alliteration, metaphor, etc., are taken into account. Within this domain, economies of comprehension do not dominate; rather it is the effects of stylistic devices on defamiliarization, feeling, and individual variations in interpretation that are critical. The two approaches also provide contrasting descriptions of how readers respond to literary devices. In text theory, both literary and non-literary discourses are regarded as amenable to the same interpretive processes (van Dijk, 1979). Features such as literary devices are regarded as "surface structures" that are transformed into propositions and then subjected to the same interpretive operations (deletion, inference, construction) as other propositions (van Dijk, 1979). In contrast, in defamiliarization theory, literary discourse presents different interpretive possibilities than nonliterary discourse, precisely because literary devices evoke feelings, defamiliarization, and an enriched mode of response. One of the central functions of literary language is thus to loosen, or to put in question, the normal relationship between the diction of the text and the referents of the words used. This is the poetic function to which Jakobson (1987) refers: The Poetic Function "deepens the fundamental dichotomy of signs and objects."Following Mukarovský (1932/1964), we refer to the literary devices that evoke these distinctive interpretive processes as foregrounding (aktualisace). Apart from a study by van Peer (1986), and some related work on narrative features (called discourse evaluations) by Hunt and Vipond (1985), foregrounding has received little experimental attention, perhaps because foregrounding has been dismissed as an intrinsic feature of literary texts. According to Schmidt (1982), 
for example, a reader processes a given text as literature only as the result of a set of extrinsically given conditions. Schmidt states that "the surface text is not aesthetic in itself until a participant judges it as such" and he regards attempts to locate attributes of literariness in the surface features of a text as an "ontological fallacy". This rejection of a long tradition in literary theory and analysis seems premature, especially since foregrounding offers a range of potentially signifierfeatures for empirical study. For example, that foregrounding occurs more frequently in literary texts than in ordinary texts can be demonstrated statistically (Dolezel, 1969). Also, the generality of readers' responses to foregrounding has yet to be determined empirically. Thus, we will continue our contrast of text theories and defamiliarization theory, but now with more detailed consideration of how readers actually respond to foregrounded text.

\section{TEXTUAL THEORY}

We propose a text theory as part of the Structural Base structure theory (SBST). The SBST is an aspiration to a text total science, what one supposes in the last analysis as a linguistic and complete scientific explication of the Reality. It is established a text theory (TT) as part of of the SBST. Linguistics text includes a textual grammar (TG), which is the sentence set grammar and it analyzes the relations in the text. The TG claims the text explication unlike the generative grammars, which only have sentence sets without having reference to the own text. It is difficult to start generating the sentences if we are situated in a broader context of the interpreter component. The TG should explain why a text is not a simple component (sentences) alination. It is necessary to analyze both the text and a difference unit of the sentence.'Language focus' is a natural dual stance to structural semantic approaches to scientific activity, and it forms a natural complement to studies in the philosophy of science (van Benthem, 2012).

All conduces to postulate three operations of the text analysis:

1) The first will be the integration in a semantic doxical superstructure (DS).

2) The second would take into account the compability between is proposed and realized. That is established between the TG and the pragmatic grammar (Carnap, 1942). It is about the relation of the signs with the interpreters or the pragmatic dimension of the semiosis.

3) The third would establish the relations for the text coherence understanding. It is concerned with the TG relations with a particular language L.

The TT is a scheme which permits us to treat ideological problems so that two components are considered: the cotextual and the contextual:

1) The grammatical structure problems belong to the cotextual component. That operates in the analysis level with its own internal information and with that taken from the text $\mathrm{T}$ that is analyzed, and it operates in the synthesis level applying the information which can be deduced from the structures carried out already.

2) The contextual component is made up of the text $T$ production and reception which is the semantic problem.

We are going to draw this fact in Figure 1. 


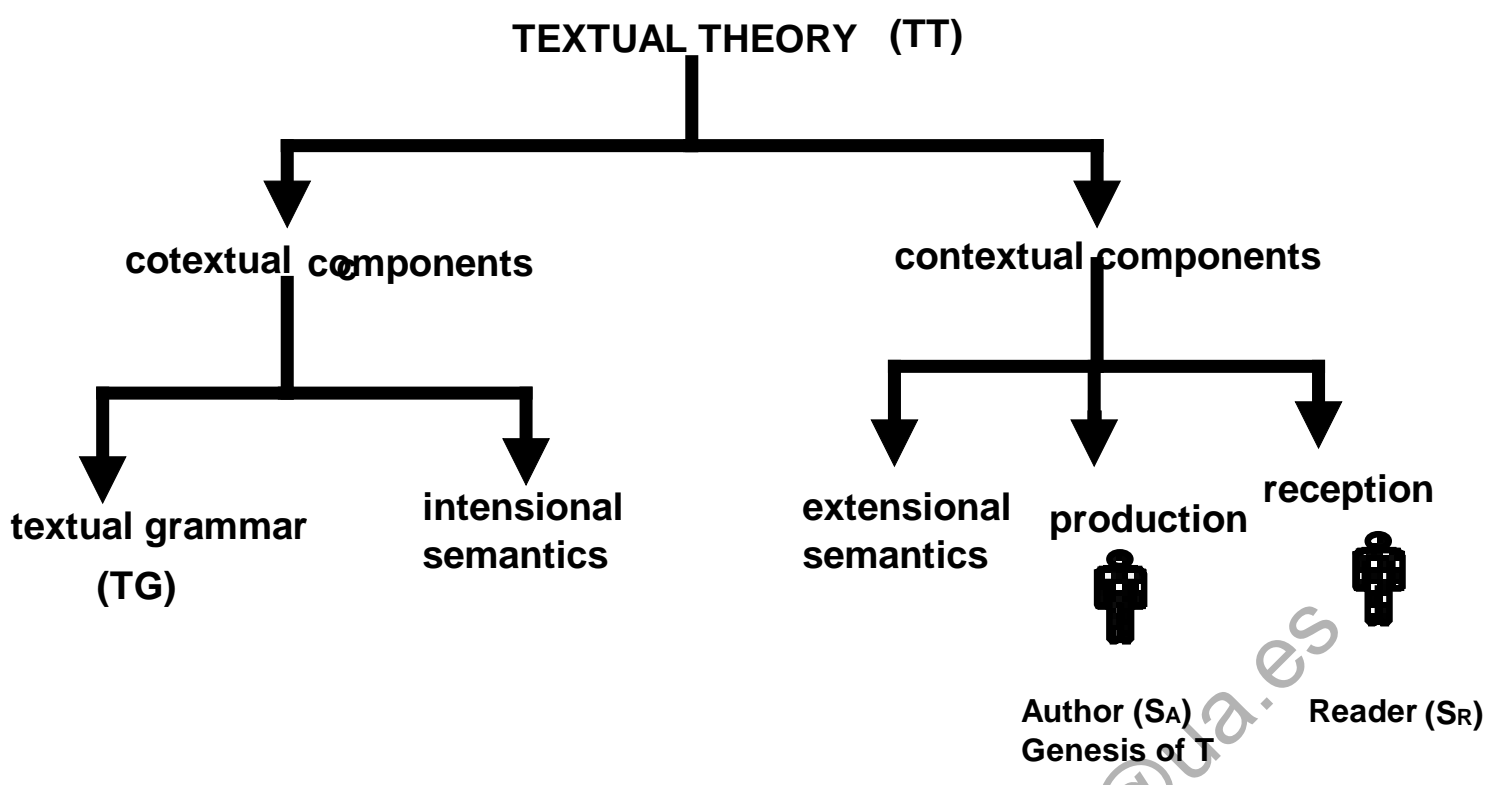

Figure 1: The two components of TT: the cotextual and the contextual.

Let there be a language $L$ and a text $T_{i}$, if the analysis applied from $T_{i}$ is originate as a textual basis (TB), being possible to obtain every textualbasis. Let $\alpha$ be an analysis. $\mathrm{TB}_{\mathrm{i} \alpha}$ will be obtained exactly. Two components can be considered in $\mathrm{t}$ :

1) TB has two aspects: a) Succession of the elemental textual units or the predicates in sentences. b) Sentence organization in larger textual units.

2) The text semantic representation (TSR) represents the intensity structure of the modeled reality and explains the contextual relations, which can be confirmed between the predicates (elemental textual units) and the informer block $T \Omega$. Its internal structure is formed by the next elements: a) The description list of the objects treated in T. b) The predicates relatives to the objects, disposed in special nets. c) The diagram where the objects between which the predicates established a relation are showed. d) The predicate order in the nets, distint by the argument or the hypothesis, T is developed in a third level of significance in the elemental units and the sentence level. e) The temporary (sometimes) relation order between the predicate content.

The basis of a text $\mathrm{T}$ is very pertinent operational aspects. Let us suppose any parcel of reality of which a text $T_{i}$ has been obtained. $T_{i}$ is analyzed and we obtain in this way $T_{i \alpha}$ or analytical base. Text $\mathrm{TB}_{\mathrm{j}}$ is obtained by a synthesis operation that is the textual base of a text $T_{j}$, which is reached from $T_{3}$ by a new synthesis. The operation for comparing or confronting is realized in the text level between $T_{i}$ and $T_{j}$, and the basis level between $\mathrm{T}_{\mathrm{i} \alpha}$ (analytical) and $\mathrm{TB}_{\mathrm{j}}$ (synthetic). The text is not compared with ontic basis, but the relation between the text and the basis only is from analysis or synthesis.

The transition from the TG components to the SBS component is the text interpretation. Every extensional interpretation results from the double operation of acceptance and modification. A value is assigned when the objects that makes up the textualized world $\mathrm{T}$ is combined with the extensional semantic predicates. Let $\sigma$ be either an object or any process: $\exists \sigma \in S B \vee \exists \sigma \notin S B$. A value (+ or -) of its existence predication will be assigned. It will also be assigned a value when the object or processes in $\mathrm{T}$ are combined with the extensional semantic predicates (true in $\mathrm{SB}_{\mathrm{i}}$, false in $\mathrm{SB}_{\mathrm{i}}$ ). The 
modification is a double operation of modification of the semantic structure of Tadjunction and change. The adjunction supposes the semantic representation of a part of $\mathrm{T}$ or subtext $\tau_{i}$. The change is the substitution of the TSR of a part of the T of another part of the T. Every $\mathrm{T}$ admits several extensional semantic interpretations, which make up its ontic basis. If any $\mathrm{SBB}_{\mathrm{i}}$ is chosen, one can observe that is made up of two different elements: an informant part $\mathrm{SB} \Phi_{\mathrm{i}}$, which points to the modifications and may be empty, that is, without modifications and a semantic representation of the ontic (SB) reality $\mathrm{SBR}_{\mathrm{i}}$, which is a TSR which has been assigned some values and that eventually has suffering certain modifications.

\section{MEDIATION, FUNCTION AND INTERPRETATION}

We have defined previously relation and deontical relations (Nescolarde-Selva, et al., 2012 a,b; Nescolarde-Selva and Usó-Doménech, 2012; Nescolarde-Selva and UsóDoménech, 2013 ${ }^{\mathrm{a}, \mathrm{b}, \mathrm{c}, \mathrm{d}, \mathrm{e}}, 2014^{\mathrm{a}, \mathrm{b}}$; Nescolarde-Selva, Usó-Doménech and Gash, 2014; Nescolarde-Selva, Usó-Doménech and Sabán, 2014; Usó-Domènech and NescolardeSelva, 2012, 2013). If we took two elements $x_{1}, x_{2}$ belonging to a Deontical Impure System $^{1}[1]$ and say that they are in relation, we make a contact of any type between both differentiated elements. The relation between $x_{1}, x_{2}$ can be or only happen explanatory if it admits that all report has an effective virtuality. The effective virtuality is the mediating action possibility between two elements $x_{1}, x_{2}$ that are in relation.

Distinction, in the conceptual level, between relation and mediation seems decisive at the time of studying a text $(\mathrm{T})$, because although the relation it can make advance in the study of the work, only the mediation can give the explanation of the same one. Is more, without a great meaning this relation usually falls in the tautology or analogy.

1) The effectiveness of a relation consists of its mediating, determining or no determining force.

2) All relation is virtually mediating because it has the effective virtuality.

3) Mediation is not only one influence, concept that locks up the causality concept.

\footnotetext{
${ }^{1}$ Impure sets are sets whose referential elements (absolute beings) are not counted as abstract objects and have the following Conditions: a) They are real (material or energetic absolute beings). b) They exist independently of the Subject. c) S develops p-significances on them. d) True things can be said about them. e) Subject can know these true things about them. f) They have properties that support a robust notion of mathematical truth. A simple impure system-linkage $\Sigma \equiv(\mathrm{M}, \mathrm{R})$ is a semiotic system consisting of the pair formed by an impure object set $\mathrm{M}$ the elements of which are p-significances (relative beings) of entities belonging to Reality (absolute beings) or certain attributes of these, and a set of binary relations, such that $\mathrm{R} \subset \mathrm{P}(\mathrm{M} \times \mathrm{x})=\mathrm{P}\left(\mathrm{M}^{2}\right)$. That is $\forall \mathrm{r} \in \mathrm{R} / \mathrm{r} \subset \mathrm{M} \mathrm{XM}$ being $r=\left\{\left(x_{i}, y_{j}\right) \in M \times M / x_{i}, y_{j} \in M\right\}$. An impure system-linkage defined within an impure object set $\mathrm{M}$ is a simple system $\mathrm{S}=(\mathrm{M}, \mathrm{R})$ or a finite union of simple systems-linkage $\Sigma=\cup_{\mathrm{i}=1}^{\mathrm{n}} \Sigma_{\mathrm{i}}$ such that $\Sigma_{\mathrm{i}}$ are simple systems. This shall be denoted as $\Sigma \equiv(\mathrm{M}, \mathrm{R})$ such that $\mathrm{R} \subset \mathrm{P}\left(\cup_{\text {finite }} \mathrm{M}^{2}\right)$. A Deontical system is an organization of knowledge on the part of the subject $S$ that fulfils the following ones: a) Other subjects (human beings) are elements of the system. b) Some existing relations between elements have Deontic modalities. c) There is purpose (purposes).
} 
4) Mediation or a relation with virtual effectiveness is the concept that tries to recover, for its possible explanation, to specificity of both abstract elements constituting all relation.

5) The effectiveness of a relation can be given or no, be happened or no, because all effectiveness is historical. That is to say, two elements $x_{1}, x_{2}$ can be in relation during certain time and a certain space, without mediation between both there is; nevertheless, as of a certain historical constituted.

Thus, we may say "There is mediating circumstances in such text (legal, literary, scientific, artistic, architectonic, etc.)", which does not mean that these circumstances determined $\mathrm{T}$, but that were gathered by the same one, perhaps in opposition to the same ones. To find the mediations of a $\mathrm{T}$ does not mean to look for the explanatory causality of the same one, but to establish the greater number of possible relations between the delimited $\mathrm{T}$ for the analysis and the circumstances that surround it and that, therefore, mediate.

If the potentiality of the relations can be determining or no determining, this distinction does not imply either the recognition of any causality, for the simple reason that all effectiveness of the relations is always historical, happens and can disappear. It is possible that an element $\mathrm{x}_{1}$ can have in an historical period all the determining effectiveness with respect to the second element $\mathrm{x}_{2}$. But also can be thought that this effectiveness can change of pole, and that the first element $\mathrm{x}_{1}$ with determining effectiveness is their time the receptive pole of the other element $\mathrm{x}_{2}$ that at this second historical moment has reached the determining effectiveness.

\subsection{Author and Reader}

All text $\mathrm{T}$ works from the communication because it communicates with the individual reader $\mathrm{S}_{\mathrm{R}}$, with the public $\left\{S_{R}\right\}$, or sector of the society, etc. According the rules of the linguistic science, the codified message is decodified by receiver $S_{R}$. The message is codified in a textual structure (TS) that, in principle, usually has its own internal laws, that is to say, its own grammar (TG). The message, text $\mathrm{T}$, and before the disappearance of the emitting author $\mathrm{S}_{\mathrm{A}}$, are a cultural unit to which all synchrony no longer can reach. For that reason; of the issuer-message-receiver triad, the message-receiver pair can only be studied, that is to say, Text-Reader $\left(T-S_{R}\right)$. At linguistic level this means that $S_{R}$ manages to decodify entirely the message. At social level, this decoding, that is diachronic, has to start off of the connotative significance and not of the denotative significance. Text $\mathrm{T}$ is eminently connotative.

Let WV be a world vision of a determined society in a historical period (NescolardeSelva and Usó-Doménech, 2013 ${ }^{\mathrm{a}}$ ) and $\mathrm{T}$ be the transmitter or text (literary, architectonic, scientific, philosophic, etc.). Let $\mathrm{WV}_{\mathrm{A}}$ and $\mathrm{WV}$, be the author and reader world vision respectively. Let c-s be the connotative significance.

The information transmitted from $S_{A}$ to $S_{R}$ is the total amount of information available in $\mathrm{S}_{\mathrm{R}}, \mathrm{I}\left(\mathrm{S}_{\mathrm{R}}\right)$, except an amount $\varepsilon$ or equivocity of the information generated in $\mathrm{S}_{\mathrm{A}}$ that a is not transmitted to $S_{R}$ being expressed as:

$$
I_{S_{A}}\left(S_{R}\right)=I\left(S_{R}\right)-\varepsilon
$$

The information generated in $\mathrm{S}_{\mathrm{A}}$ is divided in two parts: 
1) Part $\left[I_{S_{A}}\left(S_{R}\right)\right]$ that is transmitted to $S_{R}$

2) Part $\varepsilon$ that is not transmitted or equivocity.

Simultaneously, the information that is in $S_{R}$ can divide of similar way in two parts:

1) Part $\left[I_{S_{A}}\left(S_{R}\right)\right\rfloor$ represents the information received from $S_{A}$.

2) The part surplus whose source is not $S_{A}$, or noise $N$. An increase of $N$ causes that a part of the sign is hidden for $\mathrm{S}_{\mathrm{R}}$, and of this form $\left[I_{S_{A}}\left(S_{R}\right)\right]$ will decrease by means of an increase of equivocity $\varepsilon$.

$\mathrm{T}$ there is (it works) as soon as is understood, used and consumed by $\mathrm{S}_{\mathrm{R}}$. T there is by means of a relation between $S_{A}$ and $S_{R}$ habitually called communication. Therefore, communication is equivalent to equality or approach between $\mathrm{T}$ problematic and $\mathrm{S}_{\mathrm{R}}$ problematic. That is to say, is also an understanding (more or less ample), between $\mathrm{T}$ and $S_{R}$. Textual structure (TS) socially there is as soon as it works and it communicates with the society (SB). Reader $\mathrm{S}_{\mathrm{R} 1}$ decodifies only part of the message contained in $\mathrm{T}$, that is to say, the message that can understand. Another reader $S_{R 2}$ decodifies the part no understood by $S_{R 1}$, but simultaneously, $S_{R 2}$ does not undêrstand part of which first he has understood, etc. We suppose a text $\mathrm{T}$, an author $\mathrm{S}_{\mathrm{A}}$ and all the possible readers $\left\{S_{R}\right\}_{i=1, \ldots, n}=S_{R 1}, S_{R 2}, \ldots, R_{R n}$. Then:

$$
\begin{gathered}
I_{S_{A}}\left(S_{R 1}\right)=I\left(S_{R 1}\right)-\varepsilon_{1} \\
I_{S_{A}}\left(S_{R 2}\right)=I\left(S_{R 2}\right)-\varepsilon_{2} \\
\ldots \ldots \ldots \ldots \ldots \ldots \ldots \ldots \ldots \ldots \ldots \ldots \ldots \ldots \ldots \ldots \ldots \ldots \ldots \ldots \ldots \\
I_{S_{A}}\left(S_{R n}\right)=I\left(S_{R n}\right)-\varepsilon_{n}
\end{gathered}
$$

Therefore, the transmitted total information of the text $\mathrm{T}$ will be

$$
I_{S_{A}}\left(\left\{S_{R}\right\}_{i=1, \ldots, n}\right)=\bigcup_{i=1}^{n}\left(I\left(\left\{S_{R}\right\}_{i}\right)-\{\varepsilon\}_{i}\right)=\bigcup_{i=1}^{n}\left(I\left\{S_{R}\right\}_{i}\right)-\bigcup_{i=1}^{n}\{\varepsilon\}_{i}
$$

The following cases may be displayed:

1) If $W V_{S_{A}}=W S_{S_{R}}$ then $\varepsilon=0$ and $I_{S_{A}}\left(S_{R}\right)=I\left(S_{R}\right)$

2) If $W V_{S_{A}} \cong W S_{S_{R}}$ then $\varepsilon \cong 0$ and $I_{S_{A}}\left(S_{R}\right) \cong I\left(S_{R}\right)$

3) If $W V_{S_{A}} \neq W S_{S_{R}}$ then $\varepsilon \neq 0$ and $I_{S_{A}}\left(S_{R}\right)=I\left(S_{R}\right)-\varepsilon$ being as much greater $\varepsilon$ as the inequality being $W V_{S A}$ and $W V_{S B}$ is greater.

4) If $I\left(S_{R}\right)=\varepsilon$ then $I_{S_{A}}\left(S_{R}\right)=0$.

Therefore 


$$
\lim _{\varepsilon \rightarrow 0} I\left(S_{R}\right)=I\left(S_{A}\right)
$$

Let us suppose the stimulus environment $\mathbf{H}^{\prime}$ as a discreet sign-generator nil memory source $S$ and such that $S=\left\{S_{1}, S_{2}, \ldots, S_{N}\right\}$. This source therefore emits a sequence of symbols belonging to a fixed and finite alphabet (Abramson, 1980), the elements of which form a data structure. These symbols are chosen with a fixed law of probability and we will admit that they are statistically independent. The probabilities with which the symbols are presented are $p\left(S_{1}\right), p\left(S_{2}\right), \ldots, p\left(S_{N}\right)$. The amount of information generated by the occurrence of $S_{i}$ is:

$$
I\left(S_{i}\right)=\log \frac{1}{p\left(S_{i}\right)}=-\log p\left(S_{i}\right)(5)
$$

The amount of information $I\left(S_{i}\right)$ is called the surprise value of symbol $S_{i}$. The mean amount of information $I\left(S_{i}\right)$ associated with source $S$ is:

$$
\sum_{S} p\left(S_{i}\right) I(S)(6)
$$

That is, the surprise values of each one of the possibilities of source $\mathrm{S}$ are taken and weighted according to a probability of occurrence $p\left(S_{i}\right)$. The sum of everything will be the amount of information generated by the source S. If the measure of $p\left(S_{i}\right)$ is close to 1 , the amount of information associated with the occurrence of the symbol $S_{i}$ tends toward 0 . In the extreme case of the symbol's probability being 1 , the occurrence of $S_{i}$ generates no information. That is, the information is not generated by the occurrence of the symbols, so no alternative possibilities exist. We will designate as s a receptor of information in $S$. Receptor $\mathrm{s}$ is formed by the elements of lexicon $\mathfrak{I}$ that existed before the interaction in the primitive state.

How does $I(s)$ receive information from source $S$ ? We will designate this new information as $I_{S}(s)$, with the subindex $S$ indicating the part of $I(s)$ that has received information from source $\mathrm{S}$. The information transmitted from $\mathrm{S}$ to $\mathrm{s}$ is the total amount of information available in $\mathrm{s}$, that is $I(s)$ less an amount $\mathrm{R}$ or noise, which we will express as:

Similarly:

$$
\begin{aligned}
& I_{S}(s)=I(s)-R(7) \\
& I_{S}(s)=I(s)-\varepsilon(8)
\end{aligned}
$$

where $\varepsilon$ is the equivocality of the information generated by the source $\mathrm{S}$ that is not transmitted to $\mathrm{s}$. The information generated in the source $S$ is divided into two parts:

1) Part $\left[I_{s}(s)\right]$, which is transmitted to $s$.

2) Part $\varepsilon$, which is not transmitted, or equivocality.

If $\mathrm{P}$ is denoted as an operator of permission, and $\mathrm{Ph}$ the operator of prohibition, then

$$
P I(S)=\left[I_{S}(s)\right] \wedge P h I(S)=\varepsilon(9)
$$

At the same time, the information that is in $\mathrm{s}$ can be divided in the same way into two parts:

1) $\operatorname{Part}\left[I_{s}(s)\right]$, which is the information received from source $S$. 
2) The other part, the source of which is not $S$ or noise $R$. An increase of R means that a part of the sign $\mathrm{S}_{\mathrm{i}}$ is hidden, and $\left[I_{S}(s)\right]$ will thus decrease by means of an increase of the equivocality $\varepsilon$.

If the noise increases, an amount of information is lost, and the amount of information transmitted drops. Let $S$ be a signifier and $s$ the significance ${ }^{2}$ [2]. The existence of information is independent of the fact existence of a Subject able to decode the message. This objective information is termed signifier Sc. The information in a message acquires meaning if a Subject decodes the message. This subjective information is termed significance s.

In Classic Information Theory (Abramson, 1980), an equivalence is established between the noise $\mathrm{R}$ and the equivocality $\varepsilon$, as a result of having chosen the set of possibilities from the source $S$ and from the receptor s, so that $I(S)=I(s)$. If we imagine changes in the set of possibilities that define $I(s)$ without the corresponding changes in the set of possibilities that it defines $I(s)$, and vice versa, a necessary equivalence between them will not exist. In the event of there being a maximum dependency between what occurs in $\mathrm{S}$ and what occurs in $\mathrm{s}$, then $R=\varepsilon=0$ and the amount of information transmitted $\left[I_{S}(s)\right]$ will be higher and in this case $\left[I_{S}(s)\right]=I(s)$.

Let $p\left(\frac{s_{i}}{S_{i}}\right)$ be the conditional probability of a significance $s_{\mathrm{i}}$, generated in $\mathrm{s}$ based on a signifier $S_{i}$ transmitted from the source $S$. We must be able to calculate the contribution of $S_{i}$ to the noise $R$ by means of

$$
R=-\sum_{S} p\left(\frac{s_{i}}{S_{i}}\right) \log \left(p\left(\frac{s_{i}}{S_{i}}\right)\right)
$$

The equivocality $\varepsilon$ will be calculated in a similar way:

$$
\varepsilon=-\sum_{S} p\left(\frac{s_{i}}{S_{i}}\right) \log \left(p\left(\frac{s_{i}}{S_{i}}\right)\right)
$$

The flow of information is closely related to causal processes. However, it will be necessary to distinguish between the causal relations and informational relations that exist between the course (the H' stimulus environment) and the receptor, which in this case would be the deontical system. If the data were always the same, i.e. if it had experimental perseverance, which does not normally occur, a strong causal dependence would existbetween the source and receptor.

It occurs that $\left\{S_{i}\right\}$ is the cause of $\left\{S_{i}\right\}$. The significance $s_{i}$ should tell us that it occurs in the source, as $\mathrm{s}$ knows this. From the informational point of view, $\mathrm{s}$ takes more information than about what has occurred in S. Although, for a particular data structure, each symbol has a particular signifier or specific adjustment, and the temporal change of

\footnotetext{
2 In any process, we can distinguish between having a signifier as inherent property, and having significance when it is related to other processes of Reality that the Subject considers as system. The existence of information is independent of the fact that there is a Subject able to decode the message, which it is wished to communicate. This objective information is termed signifier. The information in a message acquires meaning if a Subject decodes the message. This subjective information is termed significance.
} 
this structure can determine a change in the symbol that represents it, a change made in its signifier or adjustment of the symbol and in its significance or decoding by the receiving subject.

Let $\mathrm{T}$ be a text and $\tau_{1}, \tau_{2}, \ldots, \tau_{n}$ be the subtexts so that $T=\bigcup_{i=1}^{n} \tau_{i}$. For a reading $\mathrm{S}_{\mathrm{R}}$ each one of subtexts has one connotative significance, so that $\forall \tau_{i}, \exists c-s_{i}\left(\tau_{i}\right) ; i=1, \ldots, n$. .

The connotative significance ${ }^{3}$ of a text $\mathrm{T}$ denoted as $\{c-s\}(T)$ is the union of all connotative significances of each one of its subtexts, so that $\{c-s\}(T)=\bigcup_{i=1}^{n} c-s_{i}\left(\tau_{i}\right)$.

Case 1 means the complete communication. The mediating $\mathrm{WV}_{\mathrm{T}}$ is also the world vision of the reader $\mathrm{WV}_{\mathrm{SR}}$. It is a complete communication so that there is complete equality between the connotative significances of $\mathrm{S}_{\mathrm{A}}$ and $\mathrm{S}_{\mathrm{R}}$. Everything is communicated because everything is comprehensible. It could solely exist in the more rigorous synchronous level. Case 2 is relative communication. Reader's world vision $\left(W S_{R}\right)$ does not manage to unravel all the connotations of $\mathrm{T}(\{c-s\}(T))$, but Tobtains through a series of shared correlations, to transmit its problematic one. It could solely exist in relative synchronous level. Case 3 is incomplete communication. $T$ does not manage to transmit its original problematic and for that reason it goes towards its extinction as T. T becomes document. Therefore, document is all text whose connotative significance $\{c-s\}(T)$ has changed for $S_{R}$, because their $W^{n}$ is not the same one that the existing one $\left(\mathrm{WV}_{\mathrm{i}}\right)$ when the text was conceived. The connotative significance of all text $\mathrm{T}$ always is in the synchronous level.

Case 4 is null communication. This case would happen solely when both world views is completely antagonistic or totally incomprehensible for the reader. The case of Etruscan texts is a clear example and in smaller degree, the texts of medieval alchemists.

Cases 1 and 4 are two ideal ends. Real state moves in cases 2 and 3.

\subsection{The textual function}

Nevertheless, this identification between both world views (in spite of the diachronic barrier) encounters almost immediately over the set of connotative significances. More or less delimitable polisemies in $W V_{S_{A}}$, has to be reached about $\mathrm{S}_{\mathrm{R}}$, their $W V_{S_{R}}$. Then we must introduce the concept of function of a text. The function of a Text represented as $\mathrm{F}(\mathrm{T})$ is its diachronic component, that is to say, its historical and social happen. Then $\mathrm{T}$ can:

1) To change of function: $F(T)_{0} \rightarrow F(T)_{1} \rightarrow \ldots \rightarrow F(T)_{n}$.

2) Not to work as T: $F(T)=0$.

Possibility of a pure reading of $\mathrm{T}$ could be raised; this one would only take care of the $\mathrm{WV}$ of $\mathrm{S}_{\mathrm{A}}$, but as this WV is unattainable due to passing of the time (due to the loss of the connotative significances); the possible reading would be the purely literary one (or pictorial, musicological, etc.); with which the problem becomes aesthetic. The

\footnotetext{
${ }^{3}$ Connotation is the sum of all the cultural units that the signifier can evoke institutionally in the mind of the addressee Subject whose only psychic possibility is cultural availability.
} 
exchanges of text function certain obey, as it is natural, to new WVs, appeared in SB. In this one scope the new readings, new identifications arise. But it is necessary to consider that these exchanges of function, that this new reading comes half-full by the necessities that the new reading scope feels, and not of the same $T$, the message already codified that apparently follows sound through time and space.

We can affirm that the appearance of a new social function in $T$ means the appearance of a new WS in SB.

Example 1: Don Quixote had the initial function $\mathrm{F}(\mathrm{T})_{0}$ to make laugh Spaniard people during a long period of time (centuries) and later other function $F(T)_{1}$ to make cry (Maravall, 2005).

It means that to the first Spain only decodified the easy humorism of text, and second, the one that cried, decodified the sad and the heart rendering hidden humorism (Figure 2).

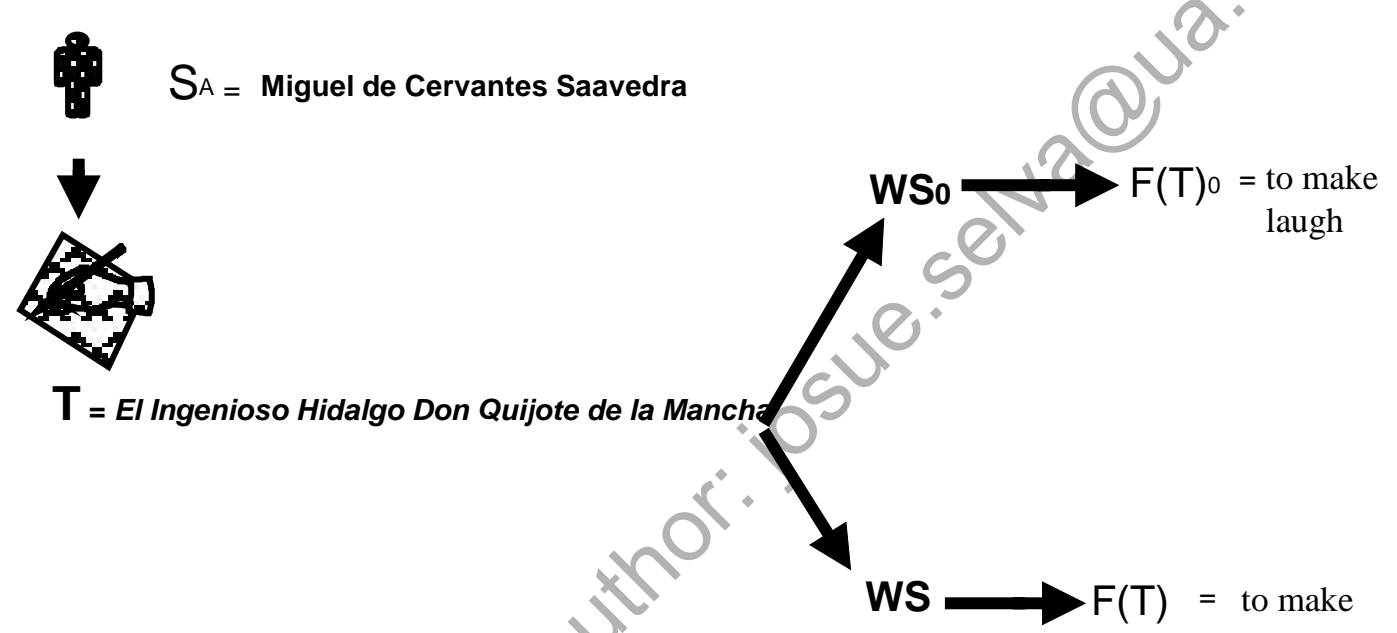

Figure 2: The case of Don Quixote.

Exchanges of $\mathrm{F}(\mathrm{T})$ are not everything in this paradoxical life of $\mathrm{T}$. There is the no function of $\mathrm{T}$ ass so, and its function as another thing (ideological object: politician, religious, philosophical, etc.). The causes of function of $\mathrm{T}$ as something not specifically textual obey to a social change in SB, to the appearance of a manipulating necessity (we did not discuss legitimacies).

Each social group must fight in all battlefields and it takes control of $\mathrm{T}$ whenever they can be interpreted in favour of ideological interests. We have exposed recently as rigorously scientists texts referring to the Ecology and Sustainable Development are being appropriate by ideological associations and manipulated in favour of their projects of society (Gershenson, 2013; Nescolarde-Selva and Usó-Doménech, 2014 ${ }^{\text {b }}$. Exchanges of $\mathrm{F}(\mathrm{T})$ mean that they are obtained or are possibilities of obtaining to identifications between different world visions.

Let $(I d)$ be the operation of identification, and $\mathrm{WV}_{1}, \mathrm{WV}_{2}, \mathrm{WV}_{3}$ be three world views and so that:

1) Reflexivity property: $W_{1}(I d) W S_{2}$

2) Antisymmetrical property: $W S_{1}(I d) W S_{2} \neg(\Rightarrow) W S_{2}(I d) W S_{1}$

3) No transitive property: $\left(W S_{1}(I d) W S_{2}\right) \wedge\left(W S_{2}(I d) W S_{3}\right) \Rightarrow W S_{1}(\neg I d) W S_{3}$ 


\subsection{The Interpretation}

Generally, text theories emphasize the reader's uncertainty about explicitly recallable meanings, whereas defamiliarization theory emphasizes the reader's affective experience of the ambiguity presented by multifaceted meanings. As Coleridge and Shklovsky anticipated, the momentarily held attention, the feeling engagement, and the suggestion of alternative interpretations prompts interpretive suspense -- at least among readers attuned to the presence of foregrounding. This expectation contrasts with that provided by text theories according to which the duration of attention to foregrounded passages allows transformation of the foregrounded text into explicitly discussable propositional form. From this perspective, momentarily held attention, transformation of foregrounding into propositions, and further interpretation of these propositions should result in greater clarity about the meanings that can be recalled and discussed with others. According to defamiliarization theory, the elaboration of richly ambiguous interpretations in response to foregrounding is guided by feeling partly because of kinesthetic components of natural metaphors (Lakoff, 1987), kinesthetic and tactile components of phonemic articulation (Fónagy, 1989), and so forth. Moreover, the elaboration of interpretations is also guided by feeling in that less familiar, less prototypic interpretations are more likely to involve personal perspectives and memories. In general, then, readers' responses to foregrounded text are likely to involve affect. As Shklovsky noted stylistic devices in literary texts "emphasize the emotional effect of an expression" (Shklovsky, 1917/1965).Given the structure of foregrounding in literary texts, we propose that, as reading continues, the affective meanings associated with foregrounding provide the basis for interpretive integration. Perhaps, somewhat as in mood-congruent remembering, readers will begin to relate passages that offer similar affective meanings. Experienced readers will also begin to anticipate the recurrence and development of certain affective meanings, perhaps only as imprecise intuitions at first, but increasingly explicitly as these recurrences accumulate. Because affect guides reinterpretation and interpretive integration, the response to foregrounding in literary texts will also involve the reader's repertoire of mood congruent, affectively signifierpersonal memories; it will, in other words, implicate the reader's self-concept (Larsen and Seilman, 1988; Miall, 1986).

In the context of Peirce's theory (Peirce, 1958) of the limitless semiosis:

1) Adl expression must be interpreted by another expression, and thus until infinity.

2) The same activity of interpretation is the only way to define contents of the expressions.

3) During this process, the socially recognized significance of the expressions grows by means of the interpretations submissive different contexts and historical circumstances.

4) The meaning of a sign is the historical chronicle of the pragmatic work that has accompanied each one by its historical appearances.

5) To interpret a sign means to anticipate all the possible contexts in that it can be introduced.

6) Semantic representation of a term is transformed into a potential text and each sememe is a rudimentary argument.

Then, sememe is a virtual text and a text is the expansion of sememe.

Transition from the TG component to the Structural Base structure (SBS) (NescolardeSelva, et al., 2012 ${ }^{\mathrm{a}, \mathrm{b}}$; Nescolarde-Selva and Usó-Doménech, 2012; Nescolarde-Selva 
and Usó-Doménech, 2013 2014; Nescolarde-Selva, Usó-Doménech and Sabán, 2014; Usó-Domènech and Nescolarde-Selva, 2012, 2013) component is the text interpretation (TI). Every extension interpretation results from the double operation of acceptance and modification. Both give the different ontic basis for the determinate texts.

Let $S_{A}, S_{R}$ be the Issuer (author) and Receiver (reader) Subjects respectively belonging to a Structural Bases $S B$ such as $I \in S B_{1} \wedge R \in S B_{2} ;\left(S B_{1}=S B_{2}\right) \vee\left(S B_{1} \neq S B_{2}\right)$ (Figure 3). Structural Bases $S B_{1}, S B_{2}$ can belong to different cultures or the same culture in different historical periods.

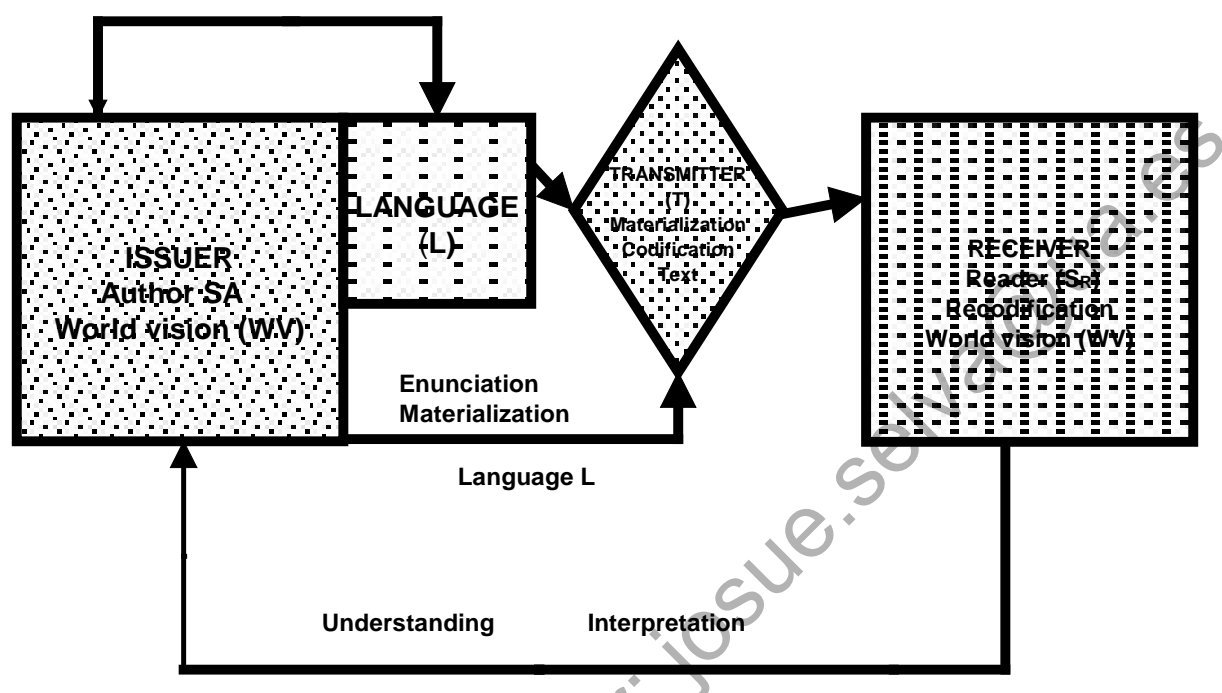

Figure 3: Text interpretation.

WV completely explains neither produced T nor the formal structure of the own work can completely explain the specificity of the materialization.

Theoretically, it is possible to be maintained that all WV can be materialized at different levels from reality. It can be materialized in the level of representation, the level of conceptualization; diverse restored levels of the social and economic behavior in Structural Base (SB). They exist the same explanatory mediations in $\mathrm{R}$ iff $\mathrm{R}$ has the same $\mathrm{WV}$ that $\mathrm{S}_{\mathrm{A}}$.

The explanatory mediations if $\mathrm{S}_{\mathrm{A}}$ is mediate by $\mathrm{WV}$ and $\mathrm{L}$. All new world vision looks for materialization immediately, since its own existence in the society has to be under materialization. Then:

1) If $S_{A}$ and $S_{R}$ have the same $W V$, there is communication between both.

2) If $S_{R}$ changes his $W V$, the communication changes its connotative significance and $S_{R}$ are dynamics.

3) If $L$ evolves, $S_{R}$ also does.

4) $S_{A}$ and $T$ are static.

Connotative projections of the DS on the structural base (SB) "justify" for the Subject actions within the structure, its extensions and substitutions or disappearance of determined world vision or, and in extreme case, the substitution of the structure by another different one.

Often, the text $\mathrm{T}$, as any other message, contains its own codes. The present reader of European medieval novels extracts such amount of slight knowledge of the denotative 
significances, on the way to think, to dress, to eat, to love, to fight, of the people of those centuries, who can perfectly reconstruct its systems of rhetorical and ideological expectations. In the own work are the keys to discover these immersed systems in the historical atmosphere where it arose. Keys to relate the message to the original codes, and it are reconstructed in a process of contextual interpretation. The same we may say for another type of messages that use iconic codes (architecture, painting, sculpture, etc.) or auditory codes (music). The interpretation is developed with a continuous oscillation (Eco, 1968), which goes from the discovery of the original codes to an attempt of faithful interpretation (reading). It is not only come to a continuous confrontation and integration of all the keys of reading, enjoying the work by this same ambiguity that is born, by the informative use of significants with respect to the original code, but by the informative use of significants related to the present codes. Each interpretation of the work, filling with meaning new the form of the original message, physically unalterable during centuries, gives to origin to new significances that enter and enrich the present codes and ideologies, reconstructing them and preparing to the reading reversions for a new interpretative situation. It is a cybernetic movement of second order, always renewed and continuous, but that cannot of any way to anticipate the concrete forms that it will adopt (Eco, 1962).

According to Eco (1990)a tricotomy articulates between:

1) Interpretation as search of the intentio auctoris (intention of the author).

2) Interpretation as search of the intentio operis (intention of the text).

3) Interpretation as imposition of the intentio lectoris (intention of the reader).

The classic debate articulates in oppositions (Figure 4):

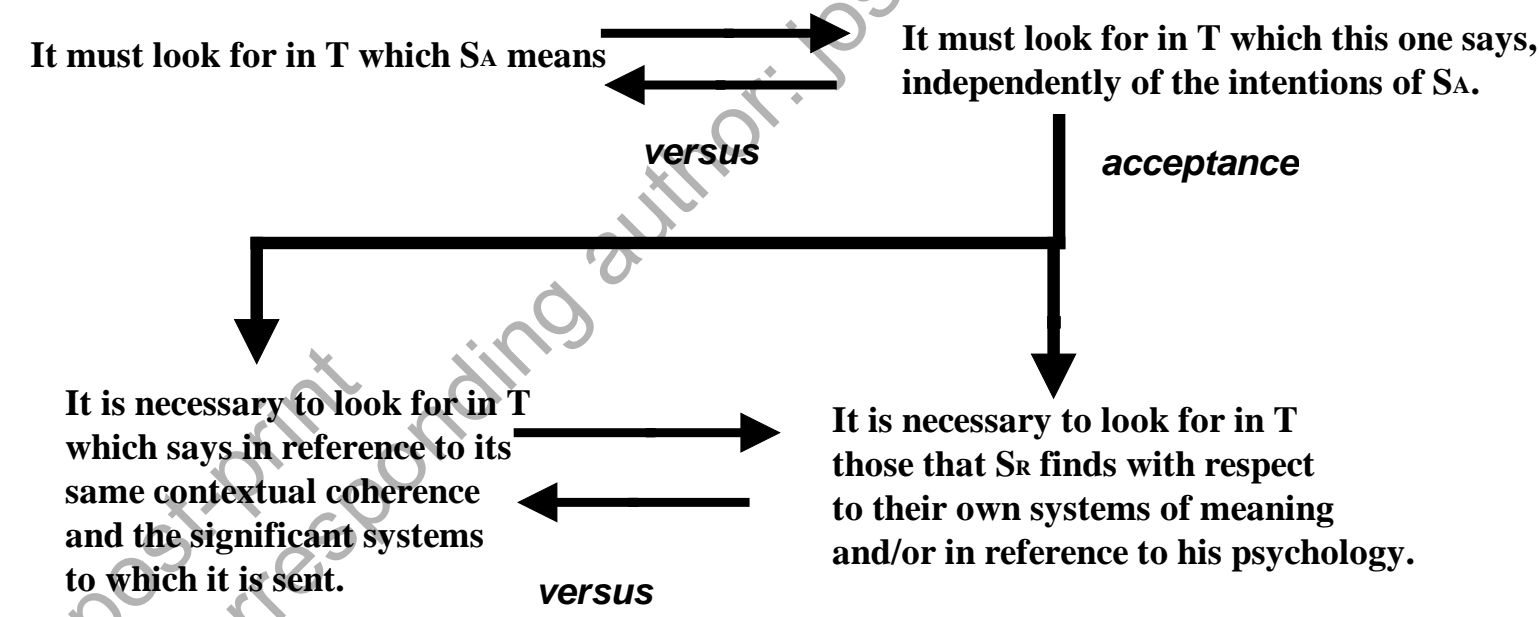

Figure 4: Oppositions in text interpretation.

A hermeneutic-symbolic reading of $\mathrm{T}$ can become according to two modalities:

1) Looking for the infinity of senses that $S_{A}$ has installed in $T$.

2) Looking for the infinity of senses that $S_{A}$ ignored (Mythical lecture).

However, saying that $\mathrm{T}$ has infinite interpretations it cannot say that this infinity is depending on intentio auctoris,intentio operis or intentio lectoris.

The significance gives sense to all the elements organized in $\mathrm{T}$, since it is the understanding of $\mathrm{T}$.

Let $\{c-s\}\left(T_{i}\right)$ be the connotative significance of subtext $\tau_{i}$. Each individual reader will have a connotative significance of text, so that: 


$$
\begin{gathered}
\{c-s\}\left(\tau_{i}\right)_{S R 1} \\
\{c-s\}\left(\tau_{i}\right)_{S R 2}(12) \\
\ldots \ldots \ldots \ldots \ldots \\
\{c-s\}\left(\tau_{i}\right)_{S R n}
\end{gathered}
$$

then

$$
\{c-s\}(T)=\bigcup_{j=1}^{n}\left(\{c-s\}\left(\tau_{i}\right)\right)_{S R j}
$$

Property 1: The total connotative significance of a $T,\{c-s\}(T)$ will be the totalization of all the possible interpretative senses of $T$.

A concrete problem appears: a new world vision not only can create new forms and new formal structures in its materialization, using the existing formal ctructures to materialize itself. It is not possible to speak of a formal structure without falling in a deep abstraction, since there is no form without contained content or without form. A net separation between formal structure is not possible and the content of the same one that is, in this case, the new world vision. The notion of applied internal laws to the formal structure of the human societies and the works that are by produced them (its cultural consequences) is inadequate due to the complexity of the treated problem. However, of some way we will have to sift the self-regulating movement of a structure, which is structure because it has its own laws or internal rules, generally deontical rules. Nevertheless, although theoretically the discovery and possession of the internal laws of a formal structure must provide the same structure, does not exist way to separate exactly forms and content, formal structure and world vision. So that this reproduction occurred, it would be necessary to also know the internal rules the new world vision. Let us suppose that it was to us present the internal laws the formal structure and the new world vision. Even so, we could not reproduce the materialization that is study object, when not sharing the world vision that inspired the materialization.

We suppose a temporal chain of world vision $W V_{1} \rightarrow W V_{2} \rightarrow \ldots \rightarrow W V_{n}$. There is no explanatory mediations ifWS $S_{1}$ has been transformed into $W_{2}$ or in $W_{n}$. The mediations are not explanatory in the level of T's function (Figure 5).

First time: Genesis of T. Mediations SB-S-T. Function F(T) 0 .

Second time: Exchange of $\mathrm{SB}$. $\mathrm{T}$ changes of function $\mathrm{F}(\mathrm{T})_{1}$. It has to have a correspondence that explains and includes: $\mathrm{WW}_{1}-\mathrm{F}(\mathrm{T})_{1}$.

Third time: Exchanges of interpretations in $\mathrm{WV}_{1}$ and $\mathrm{WV}_{2}$, and correlative exchanges of function $\mathrm{F}(\mathrm{T})_{2}$ : $\mathrm{WW}_{2}-\mathrm{F}(\mathrm{T})_{2}$.

If $\mathrm{WV}_{0}$ can arrive at $\mathrm{WV}_{\mathrm{n}}$, $\mathrm{T}$ remains immobile.

$\mathrm{T}$ is lost its function $\mathrm{F}(\mathrm{T})_{\mathrm{n}}=0$. Nevertheless, $\mathrm{WV}_{\mathrm{n}}$ continues interpreting $\mathrm{T}$ historically. Process of documenting, or development of the understanding and interpretation of $\mathrm{T}$ comes given in figure 6 . 


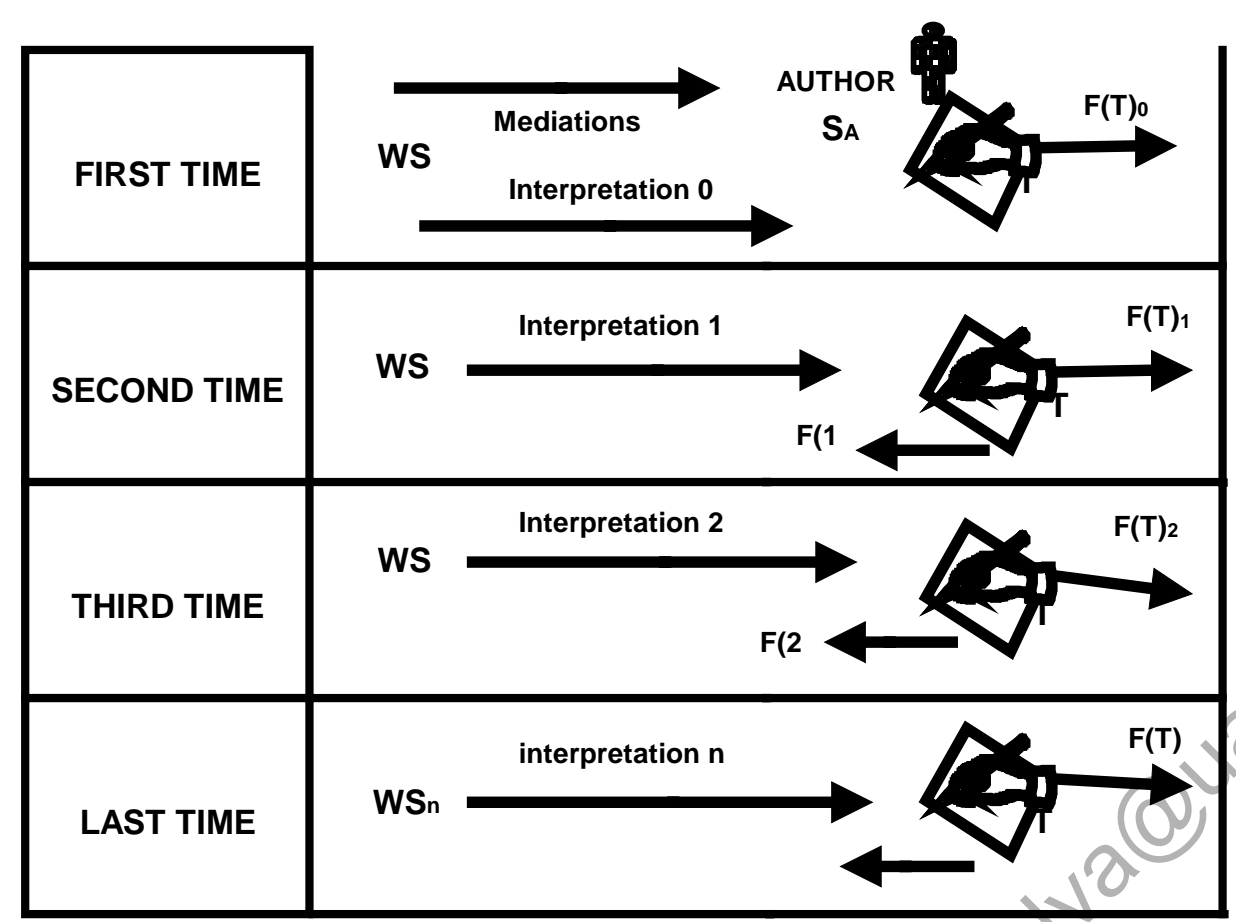

Figure 5: Not explanatory mediations in the level of T's function.

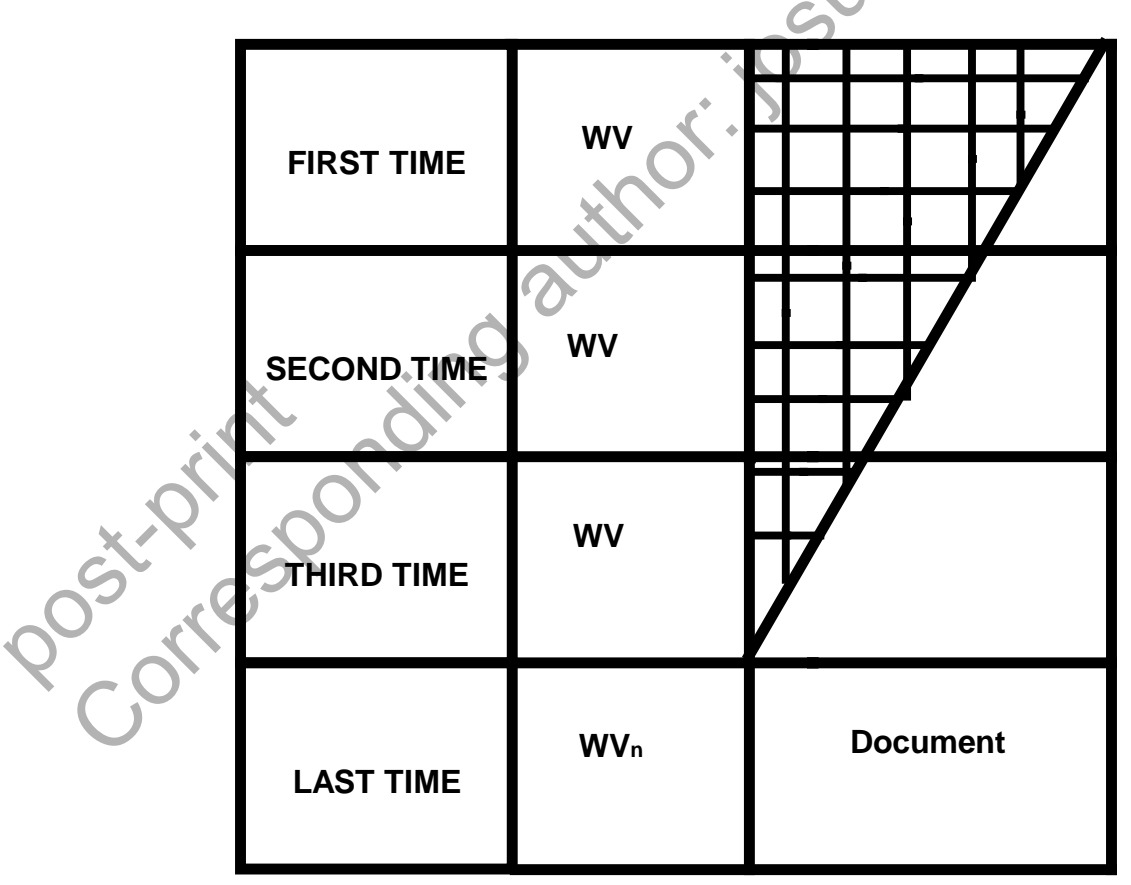

Figure 6: The process of documenting.

The process of exchange of the value of $\mathrm{T}$ comes given in figure 7 : 


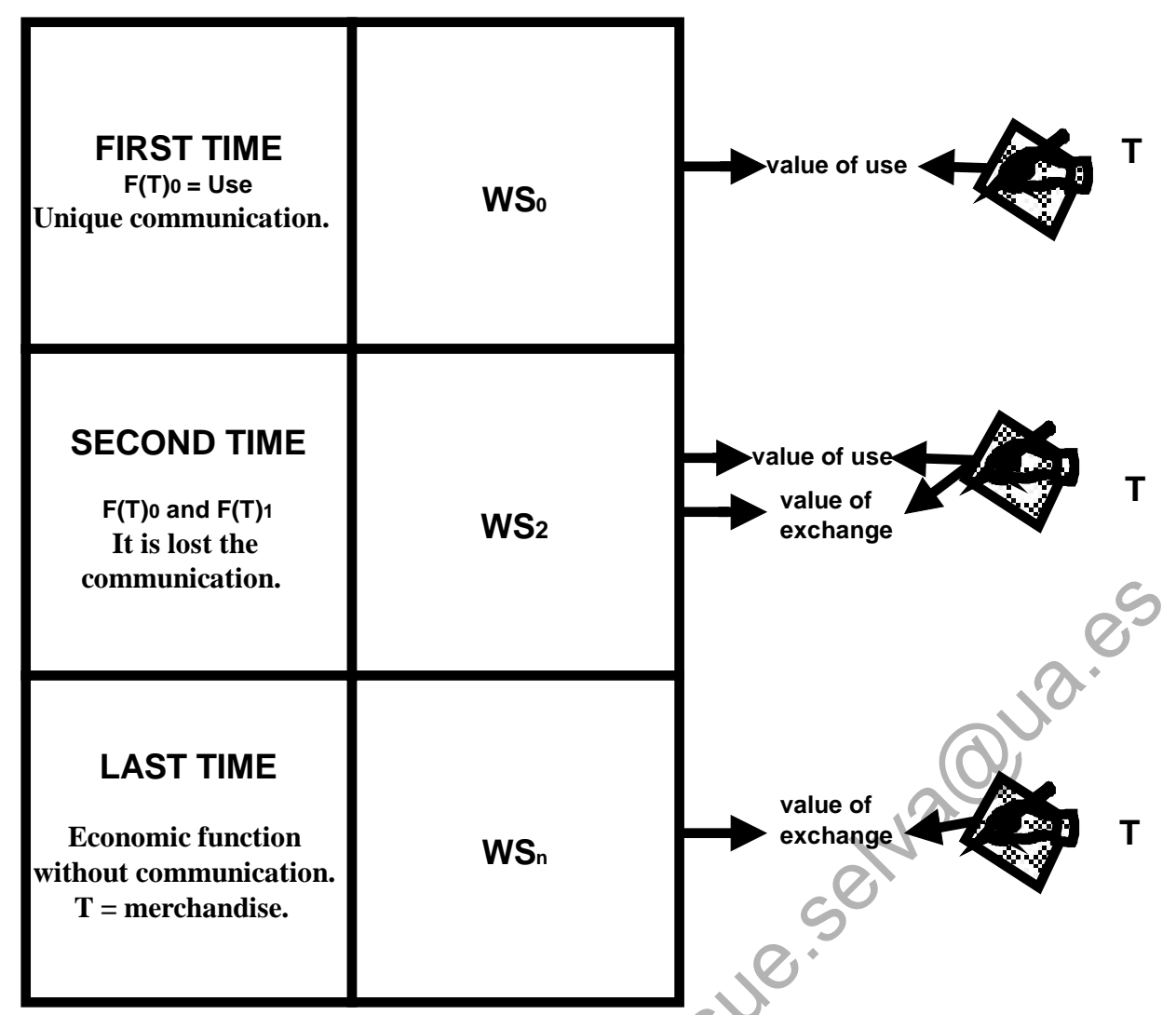

Figure 7: The process of exchange.

It is necessary to admit that all $\mathrm{T}$ is born, grows, reproduces (or not) and finally dies; and this mortal life, as all human work, we can be found with exchanges of function, manipulations, etc., and to the fine one, inevitably, with a death, that can be sad and lamentable, but, in other cases, it can console. Little people, we believe, can lament the death of some texts as The Protocols of the Elders of Zion, Mein Kampf or buildings of the Inquisition. Second Law of Thermodynamic (Entropy) operates in text T, as much at physical level (deterioration or destruction) like a informative level (loss of its connotative significance).

\section{TOPOLOGICAL TEXTUAL STRUCTURES}

In all text T we can observe diverse mathematical structures.

\subsection{The Metric Textual Space}

Let $\tau$ be a set of subtexts $\tau=\left\{\tau_{1}, \tau_{2}, \ldots, \tau_{n}\right\}$ and $\varnothing$ be the empty text. Let $\mathrm{d}$ be a metric on $\mathrm{T}$, that is, a function $\mathrm{d}$ : $\mathrm{TxT} \rightarrow \mathrm{R}$ such that for any $\tau_{1}, \tau_{2}, \tau_{3} \in T$. Function $d$ is also called distance textual function or simply textual distance. We establish the following properties:

1. Non-negativity: $d\left(\tau_{1}, \tau_{2}\right) \geq 0$.

2. Identity of indiscernibles: $d\left(\tau_{1}, \tau_{2}\right)=0$ iff $\tau_{1}=\tau_{2}$.

3. Symmetry: $d\left(\tau_{1}, \tau_{2}\right)=d\left(\tau_{2}, \tau_{1}\right)$.

4. Triangle inequality: $d\left(\tau_{1}, \tau_{3}\right) \leq d\left(\tau_{1}, \tau_{2}\right)+d\left(\tau_{2}, \tau_{3}\right)$.

5. The first condition follows from the other three, since: $2 d\left(\tau_{1}, \tau_{2}\right)=d\left(\tau_{1}, \tau_{2}\right)+d\left(\tau_{2}, \tau_{1}\right) \geq d\left(\tau_{1}, \tau_{1}\right)$. 
Property 2: The ordered pair $(T, d)$ forms a metric spacethat we will denominate metric textual space (MTS).

Definition 1: A subset $\tau$ of MTS $(T, d)$ is called open if, given any textual point $x_{1} \in \tau$, there is a real number $\varepsilon>0$ such that, given an textual point $x_{2} \in T$ with $d\left(x_{1}, x_{2}\right)<\varepsilon, x_{w} \in \tau$.

Equivalently, $\tau$ is open if every textual point in $\tau$ has a neighborhood contained in $\tau$. Let $T=\left\{\tau_{1}, \tau_{2}, \ldots, \tau_{n}\right\}$ be a set and $\mathbf{T}$ be a collection of subsets of $\mathrm{T}$ as $\mathbf{T}$ $=\left\{\{\},\left\{\tau_{1}\right\}, \ldots\left\{\tau_{n}\right\},\left\{\tau_{1}, \tau_{2}\right\}, \ldots,\left\{\tau_{1}, \ldots, \tau_{n}\right\}\right\}$.

Note 1: Subsets $\tau_{i}$ will be defined as subtexts.

\subsection{The Textual Topology}

Topological structures are based on (Bredon, 1997; Munkres, 1999; Willard, 2004; Samsonovich, et.al., 2009; Klüver, 2011). Different authors formulate the hypothesis that all text has topological properties (Bredon, 1997; Munkres, 1999; Willard, 2004).

Definition 2: The collection $\mathbf{T}$ is called a textual topology (TP) on $T$.

Definition 3: A topological textual space (TTS) is aset T together with a collection Tof subtexts of $T$ satisfying the following axioms:

Axiom 1: $\varnothing \in \mathbf{T}$ and $T \in \mathbf{T}$.

Axiom 2: The union $\bigcup$ of any pair of subtexts $\left(\tau_{i}, \tau_{j}\right) \in$ Tis also inT. E.g. $\tau_{i} \cup \tau_{j} \in \mathbf{T}$

Axiom 3: The intersection of any finite collection of subtexts $\tau_{1}, \tau_{2}, \ldots, \tau_{n} \in$ Tis also in T. E.g. $\tau_{1} \cap \tau_{2} \cap . . \cap \tau_{n} \in \mathbf{T}$

Under this definition, the sets in the textual topology $\mathbf{T}$ are the closed subtexts, and their complements in Tare the open subtexts.

Definition 4: Using the Kuratowski closure axioms a TTS (T,cl)is a set $T c l: P(T) \rightarrow T$ where $P(T)$ is the power set of $T$ and with a function cl called closure textual operator satisfying the following properties:

1) Extensivity: $\tau_{1} \subseteq \operatorname{cl}\left(\tau_{1}\right)$

2) Idempotence: $\operatorname{cl}\left(\mathrm{cl}\left(\tau_{1}\right)\right)=\operatorname{cl}\left(\tau_{1}\right)$

3) Preservation of binary unions: $\operatorname{cl}\left(\tau_{1}\right) \cup \operatorname{cl}\left(\tau_{2}\right)=\operatorname{cl}\left(\tau_{1} \cup \tau_{2}\right)$

4) Preservation of nullary unions: $\operatorname{cl}(\varnothing)=\varnothing$

5) Preservation of finitary unions: $\operatorname{cl}\left(\tau_{1} \cup \tau_{2} \cup \ldots \cup \tau_{n}\right)=\operatorname{cl}\left(\tau_{1}\right) \cup \operatorname{cl}\left(\tau_{2}\right) \cup \ldots \cup \operatorname{cl}\left(\tau_{n}\right)$

Let $\tau$ be a subtext and $x \in \tau$ be a textual point. 
Definition 5: A textual point $x \in \tau$ is called closed in (T,cl) iff $x \in \operatorname{cl}(\tau)$

Definition 6: A subtext $\tau$ is called closed subtext in (T, cl) iff $\tau=\operatorname{cl}(\tau)$

Definition 7: A textual cover $C$ of $T$ is the collection of subtexts $U_{\alpha}$ of $T$ whose union is the whole textual space T. E.g.T $=\bigcup U_{\alpha}$. In this case we say that $C$ textually covers $T$, or that the subtexts $U_{\alpha}$ cover $T$.

If $\tau$ is a subtext of $\mathrm{T}$, then a textual cover of $\tau$ is a collection of subtexts of $\mathrm{T}$ whose union contains $\tau$, i.e., $C$ is a textual cover of $\tau$ if $\tau \subseteq \bigcup U_{\alpha}$.

Definition 8: A textual subcover $\square$ of $C$ is the subtext of $C$ that still textually covers $T$.

Definition 9: $C$ is an open textual cover if each of its members is an open subtext, i.e. each $U_{\alpha}$ is contained in $\mathrm{T}$, where $\mathrm{T}$ is the textual topology on $\mathrm{T}$.

Let $\mathrm{x}$ be a textual point in $\mathrm{T}$.

Definition 10: The interior of a text $\mathrm{T}$ denoted int( $T$ ) is the set of all interior textual points of $T$.

The interior of a text has the following properties.

1) $\operatorname{int}(T)$ is an open subtext of $T$.

2) $\operatorname{int}(T)$ is the union of all open subtexts contained in $T$.

3) $\operatorname{int}(T)$ is the largest open set contained in $T$.

4) A text $T$ is open iff $T=\operatorname{int}(T)$.

5) Idempotence: $\operatorname{int}(\operatorname{int}(T))=\operatorname{int}(T)$.

6) If $\tau$ is a subtext of $T$, then int $(\tau)$ is a subtext of $\operatorname{int}(T)$.

7) If $\tau$ is an open subtext, then $\tau$ is a subtext of $T$ iff $\tau$ is a subtext of $\operatorname{int}(T)$.

Definition 11: The exterior of a subtext $\tau$ of a topological textual space $T$, denoted $\operatorname{ext}(\tau)$, is the interior int $(T / \tau)$ of its relative complement.

Definition12: $T \backslash \tau^{-}$, is the complement of the closure of $T$.

Properties are the following:

1) $\operatorname{ext}(\tau)$ is an open subtext that is disjoint with $\tau$.

2) $\operatorname{ext}(\tau)$ is the union of all open subtexts that are disjoint with $T$.

3) $\operatorname{ext}(\tau)$ is the largest open subtext that is disjoint with $T$.

4) If $\tau^{\prime}$ is a subtext of $\tau$, then $\operatorname{ext}\left(\tau^{\prime}\right)$ is a supertext of $\operatorname{ext}(\tau)$.

5) $\operatorname{ext}(\operatorname{ext}(\tau))$ is a supertext of $\operatorname{int}(\tau)$.

Definition 13: A textual neighborhood of $\mathrm{x}$ is a subtext $\tau$, which contains an open subtext containing $x, x \in v \subseteq \tau$. 
Definition 13 is also equivalent to $x \in T$ being in the interior of $\tau$.Note that the textual neighborhood need not be an open subtext itself. If is open it is called an open textual neighborhood. A subtext which is a textual neighborhood of each of its textual points is open since it can be expressed as the union of open subtexts containing each of its textual points.

Definition14: Textual neighborhood filter $\square(x)$ for a textual point xis the collection of all textual neighborhoods for the textual point $x$.

Definition 15: The collection of all textual neighborhoods of a textual point $x$ is called the textual neighborhood system at the textual point $x$.

1) If $\tau$ is a subtext of $T$ then a textual neighborhood of $\tau$ is a subtext $v$ which contains an open subtext $\omega$ containing $\tau$.

2) A subtext $\tau$ is a textual neighborhood of $v$ iff it is a textual neighborhood of all the points in $\tau$.

3) $v$ is a textual neighborhood of $\tau$ iff $\tau$ is a subset of the interior of $v$.

Definition 16: A collection of subtexts of a topological textual space $T$ is said to be locally finite, if each textual point in the textual space has a textual neighborhood that intersects only finitely many of the subtexts in the collection.

Definition 17: A topological textual space $T$, is said to be locally finite if every collection of subtexts of it is locally finite.

Theorem 1: Textual topological space $T$ is a finite space.

Proof:

Since every locally finite collection of textual points is point finite, every collection of subtexts of $\mathrm{T}$ must be point-finite. The power set of $\mathrm{T}$ must be finite, because if it were infinite, the collection of all subtexts of $\mathrm{T}$ would not be locally finite since some textual point would belong to infinitely many subtexts of $\mathrm{T}$. This means that $\mathrm{T}$ is finite.

Consequence 1: $T$ is locally finite iff it is finite.

Definition 18: TextT is a trivial textual topology, in which only the empty text and the whole space TTS are open.

Every sequence and net in this textual topology $\mathrm{T}$ converges to every textual point of the space.

Definition 19: Textual base $B_{T}$ for a topological textual space $T$ with textual topology Tis the collection of open sets in $\boldsymbol{T}$ such that every open set in $\mathbf{T}$ can be written as a union of elements of $B_{T}$.

The textual base generates the textual topology $\mathrm{T}$. The properties of textual bases are:

Property 3: The base elements cover T.

Let $B_{\mathrm{T} 1}, B_{\mathrm{T} 2}$ be base elements and let $I$ be their intersection $I=B_{T 1} \cap B_{T 2}$. 
Property 4: For each $x$ in $I$, there is another base element $B_{3}$ containing $x$ and contained in $I$.

If a collection $\tau=\left\{\tau_{1}, \tau_{2}, \ldots, \tau_{n}\right\}$ of subtexts of $T$ fails to satisfy either of these properties, then it is not a base for any topology on $T$. Conversely, if $\tau$ satisfies both of the properties 3 and 4, then there is a unique textual topology on $T$ for which $\tau$ is a base; it is called the textual topology generated by $\tau$, being this textual topology the intersection of all topologies on $T$ containing $\tau$.

Limit points are unique in TTS and are required to be a Hausdorff spaces.

For Property 4, T forms a metric textual space MTS. Every MTS can be given a metric textual topology MTT, in which the basic open textual sets are open balls defined by the textual metric TM. This is the standard topology on any normed vector textual space (NVTS. On a finite-dimensional vector space as they are TTS this topology is the same for all norms.

Let $\left(T_{1}, c l_{1}\right),\left(T_{2}, c l_{2}\right)$ be two TTSs.

Definition 20: $\left(T_{2}, c l_{2}\right)$ is the interpretation of $\left(T_{1}, c l_{1}\right)$ to the continuous function $f_{\text {int }}:\left(T_{1}, c l_{1}\right) \rightarrow\left(T_{2}, c l_{2}\right)$ where $\forall \tau \in T / f_{\text {int }}\left(c l_{1}(\tau)\right) \odot c l_{2}\left(f_{\text {int }}(\tau)\right)$

Let $\tau_{\mathrm{i}}$ and $\tau_{\mathrm{j}}$ be two subtexts on a text such $\tau_{i} \subseteq \tau_{j}$. That is, every element of $\tau_{\mathrm{i}}$ is also an element of $\tau_{j}$. Then the textual topology $\tau_{i}$ is said to be a coarser textual topology than $\tau_{\mathrm{j}}$, and $\tau_{\mathrm{j}}$ is said to be a finer textual topology than $\tau_{\mathrm{i}}$. If $\tau_{i} \neq \tau_{j}$ we say $\tau_{\mathrm{i}}$ is strictly coarser than $\tau_{\mathrm{j}}$ and $\tau_{\mathrm{j}}$ is strictly finer than $\tau_{\mathrm{i}}$. The binary relation $\tau_{i} \subseteq \tau_{j}$ defines a partial ordering relation on the set of all possible topologies on $\mathrm{T}$. The following statements are equivalent:

1) $\tau_{i} \subseteq \tau_{j}$.

2) The identity map $\operatorname{id}_{T}:\left(T, \tau_{j}\right) \rightarrow\left(T, \tau_{i}\right)$ is a continuous map.

3) The identity map $i d_{T}:\left(T, \tau_{i}\right) \rightarrow\left(T, \tau_{j}\right)$ is closed map.

Given a topological textual space $(T, c l)$ and a subset $\tau$ of $T$, the subspace textual topologycon $T$ is defined by $c_{T}=\{T \cap \tau \mid \tau \in c l\}$. Alternatively we can define the subspace textual topology for a subset $\tau$ of $T$ as the coarsest topology for which the inclusion map $i: T \rightarrow \tau$ is continuous. We suppose $i$ is an injection from a set $\tau$ to a topological textual space $T$. Then the subspace textual topology on $\tau$ is defined as the coarsest topology for which $i$ is continuous.

Property 5: Each subtext $\tau_{i}$ will form as well, a topological textual subspace.

Let $\tau_{2}$ be a subtext of $\tau_{1}$ and let $i: \tau_{2} \rightarrow \tau_{1}$ be the inclusion map. Then for any TTM $\tau_{3}$ a map $f: \tau_{3} \rightarrow \tau_{2}$ is continuous iff the composite map i $\circ$ is continuous. This property is characteristic in the sense that it can be used to define the subspace topology on $Y$.

Let $S \tau_{2}$ be a subtext of $X \tau_{1}$.

1) If $f: \tau_{1} \rightarrow \tau_{3}$ is continuous the restriction to $\tau_{2}$ is continuous.

2) If $f: \tau_{1} \rightarrow \tau_{3}$ is continuous then $f: \tau_{1} \rightarrow f\left(\tau_{1}\right)$ is continuous. 
3) The closed sets in $\tau_{2}$ are precisely the intersections of $\tau_{2}$ with closed sets in $\tau_{1}$.

4) If $\tau_{4}$ is a subtext of $\tau_{2}$ then $\tau_{4}$ is also a subtext of $\tau_{1}$ with the same textual topology.

5) Suppose $\tau_{2}$ is an open subtext of $\tau_{1}$. Then a subtext of $\tau_{2}$ is open in $\tau_{2}$ iff it is open in $\tau_{1}$.

6) Suppose $\tau_{2}$ is a closed subtext of $\tau_{1}$. Then a subtext of $\tau_{2}$ is closed in $\tau_{2}$ iff it is closed in $\tau_{1}$.

7) If $B_{\tau 1}$ is a textual base for $\tau_{1}$ then $B_{\tau 2}=\left\{v \cap \tau_{2}: v \in B_{T}\right\}$ is a textual basis for $\tau_{2}$.

8) The topology induced on a subset of a metric textual space MTS by restricting the textual metric TM to this subset coincides with subspace textual topology for this subset.

Let $\mathrm{T}_{1}, \mathrm{~T}_{2}$ be two texts

Corollary 1: A continuous map $f: T_{1} \rightarrow T_{2}$ remains continuous if the textual topology on $T_{2}$ becomes coarser or the textual topology on $T_{1}$ finer.

Corollary 2: A closed map $f: T_{1} \rightarrow T_{2}$ remains closed if the textual topology on $T_{2}$ becomes finer or the textual topology on $T_{1}$ coarser.

Each subtext will be formed by other smaller subtexts. The very small one or infimum will be the unit containing the basic semantic unit. In texts written it will be the word and we denote as $\inf \tau$. The greatest element of $\tau$ or supremum will be the own $\tau$ and we denote as $\sup \tau$. Every subset of a TTS can be given the subspace textual

Definition 21: The Cartesian product of the topological textual spaces $T_{i}$, is the product $T=\prod_{i=1}^{n} T_{i}$

Let $P_{i}: T \rightarrow T_{i}$ be the canonical projections

Definition 22: Tychonoff textual topology on $T$ is defined to be the coarsest textual topology for which all the projections $P_{i}$ are continuous.

Let $U$ be an open subset of $\mathrm{T}_{\mathrm{i}}$.

Definition 23: The product textual topology on $T$ is the textual topology generated by textual sets of the form $P_{i}^{-1}(U)$.

Sets $\left\{P_{i}^{-1}(U)\right\}$ form a subbase for the textual topology on $T$

Let $\left\{\tau_{1}, \tau_{2}, \ldots, \tau_{n}\right\}$ be an indexed family of subtexts (topological textual subspaces).

Definition 24:A textual basis consists of textual sets $\prod_{i} U_{i}$, where for cofinitely or finitely many $i, U_{i}=T_{i}$, and otherwise it is a basic open set of $T_{i}$. 
For a finite product the products of base elements of the $T_{i}$ gives a textual basis for the product.

Let $\mathrm{T}$ be a textual topological space and $\tau=\left\{\tau_{1}, \tau_{2}, \ldots, \tau_{n}\right\}$ be a set of subtexts.

Definition 25: A textual quotient space if $f: T \rightarrow \tau$ is a surjective function, then the quotient topology on $\tau$ is the collection of subtexts of $\tau$ that have open inverse images under $f$.

The textual quotient topology is the finest topology on $\tau$ for which $f$ is continuous.

\subsection{The Textual Lattice}

Definition 26: The partially ordered set $(T, \subseteq)$ is a complete textual lattice if every subset $\tau \in T$ has both a infimuminf $\tau$ and a supremum $\sup \tau$ in $(T, \subseteq)$.

Let $\left\{\tau_{i}\right\}$ be a collection of textual topologies (subtexts). Then:

1) The infimum of a collection of textual topologies is the intersection of those textual topologies $\inf \left\{\tau_{i}\right\}=\bigcup_{i=1}^{n} \tau_{i}$.

2) The supremum, however, is not generally the union of those textual topologies but rather the topology generated by the union, that is to say, plaintext $\mathrm{T}$.

A complete textual lattice is also a bounded lattice, which is to say that it has a greatest element being a discrete topology and least element being a trivial topology.

\section{CONCLUSIONS}

In previous papers (Nescolarde-Selva and Usó-Doménech, 2013 ${ }^{\mathrm{c}, \mathrm{d}}$ ) we have tried to demonstrate that the connected beliefs have a mathematical structure, a topological structure concretely. This fact could appear like a mere academic disquisition of an abstract theory without any practical application. But in fact it is very different. The ideas, the beliefs are pronounced in written, architectonic, pictorial, musical, etc., texts. Speech of literary, architectonic, artistic styles, differentiated clearly according to historical times, corresponding to the world visions of the people who lived in those periods. These cultural products are, in fact, materializations of the belief abstract systems and nobody can deny that all of them have a geometric, topological structure. We have tried to demonstrate that the textual materializations are the existing projections between an abstract topology and a concrete topology, with the addition of an auxiliary dimension: the meaning.

We thought to have demonstrated that any text has mathematical structures but, what consequences have the existence of these structures? The possibility of establishing a theory of materialization of belief systems through constructed texts. This materialization would settle down through other mathematical structures such as nets between substantive beliefs and the own text. In conclusion, we have argued that understanding response to literary texts requires a different approach: theories developed in studies of normal prose are too limited for the purpose, even where these are supplemented by attention to affective elements of structure, plot, or content. But we also suggest that studying literary response offers the opportunity to explore the functions and processes of feeling, and to do so with a richness and complexity, and 
with mathematical and logical validity, that is perhaps unavailable elsewhere. Research in this field may cast light not only on readers' responses to literary style, but also on the little understood means by which the distinctive language of literature fosters changes in the way we understand our personal life-worlds.

\section{REFERENCES}

Abramson, N. Information Theory and Coding. McGraw-Hill Book Company, Inc. 1980.

Bredon, G. E. 1997. Topology and Geometry. Graduate Texts in Mathematics. Springer.

Carnap, R. Introduction to semantics. Harvard University Press. 1942 (Reprinted 1958).

Coleridge, S. T. 1983. Biographia literaria, 2 Vols. J. Engell \& W. J. Bate (Eds.). London: Routledge \& Kegan Paul. (Original work published 1817.)

Dolezel, L. 1969. A framework for the statistical analysis of style. In L. Dolezel \& R. W. Bailey (Eds.), Statistics and style (pp. 10-25). New York: American Elsevier.

Eco, U. 1962.Opera aperta. Bompiani. Milano. (In Italian)

Eco, U. 1968. La struttura assente. Casa Editrice Valentino Bompiani \& C.S.p.A. (In Italian)

Eco, U. 1990.I limiti dell'interpretazione. Grupo Editoriale Fabbri, Bompiani, Sonzogno, Etas S.p. Milan. (In Italian).

Fónagy, I. 1989. The metaphor: a research instrument. In D. Meutsch \& R. Viehoff (Eds.), Comprehension of literary discourse (pp. 111-130). Berlin: Walter de Gruyter.

Gershenson, C. 2013. Collaborations: The fourth age of research. Complexity. DOI: 10.1002/cplx.21451. Vol 19,1.1-5.

Hunt, R., and Vipond, D. 1985. Crash-testing a transactional model of literary reading. Reader: Essays in Reader-Oriented Theory, Criticism, and Pedagogy, 14, 2339.

Kintsch, W. 1988. The role of knowledge in discourse comprehension: A constructionintegration model. Psychological Review, 95, 163-182.

Kintsch, W., \& van Dijk, T. A. 1978. Toward a model of text comprehension and production. Psychological Review, 85, 363-394.

Klüver, J., 2011. A mathematical theory of communication: Meaning, information, and topology. Complexity. Vol. 16. Issue 3. pp: 10-26.

Lakoff, G. 1987. Women, fire, and dangerous things. Chicago: University of Chicago Press. 
Larsen, S. F. and Seilman, U. 1988. Personal reminding while reading literature. Text, 8, 411-429.

Miall, D. S. 1986. Emotion and the self: The context of remembering. British Journal of Psychology, 77, 389-397.

Maravall., J.A. 2005.Utopía y contrautopía en el Quijote. Prologue by Ramón Menéndez Pidal. Centro de Estudios Políticos y Constitucionales. Madrid. (In Spanish).

Munkres, J. Topology. Prentice Hall. 1999.

Mukarovský, J. 1964. Standard language and poetic language. In P. L. Garvin (Ed.), A Prague School reader on esthetics, literary structure, and style (pp.517-30). Washington, DC: Georgetown University Press. (Original work published 1932.)

Nescolarde-Selva, J., Vives Maciá, F., Usó-Doménech, J.L., Berend, D. 2012 .An introduction to Alysidal Algebra I. Kybernetes 41(1/2), pp. 21-34.

Nescolarde-Selva, J., Vives Maciá, F., Usó-Doménech, J.L., Berend , D. 2012 .An introduction to Alysidal Algebra II. Kybernetes. 41(5/6), pp.780-793.

Nescolarde-Selva, J., Usó-Doménech. J. L. 2012 . An introduction to Alysidal Algebra III. Kybernetes. 41(10), pp. 1638-1649.

Nescolarde-Selva, J. and Usó-Domènech, J. L. 2013 ${ }^{\text {a }}$ Semiotic Vision of Ideologies. Foundations of Science. DOI 10.1007/s10699-013-9329-9. 19 (3). pp. 263-282.

Nescolarde-Selva, J. A. and Usó-Doménech, J. L. 2013 ${ }^{\mathrm{b}}$ Reality, System and Impure Systems. Foundations of Science. DOI: 10.1007/s10699-013-9337-8. 19 (3). pp. 289306.

Nescolarde-Selva, J. and Usó-Doménech, J. L. 2013‥ Topological Structures of Complex Belief Systems. Complexity. DOI: 10.1002/cplx.21455. Vol 19, 1. 46-62.

Nescolarde-Selva, J. and Usó-Doménech, J. L 2013 ${ }^{\mathrm{d}}$. Topological Structures of Complex Belief Systems (II): Textual Materialization. Complexity. Vol. 19, 2. 50-62

Nescolarde-Selva, J. and Usó-Doménech, J. L. 2013 - An introduction to Alysidal Algebra V: Phenomenological components. Kybernetes. Vol. 42 (8). pp. 1248 - 1264.

Nescolarde-Selva, J.A. and Usó-Doménech, J.L. 2014 ${ }^{\mathrm{a}}$. Myth, language, and complex ideologies. Complexity. DOI: 10.1002/cplx.21506.

Nescolarde-Selva, J.A. and Usó-Doménech, J.L. 2014ํㅡ. Ecosustainability as Ideology. American Journal of Systems and Software. Vol 2. No 1. 14-21.

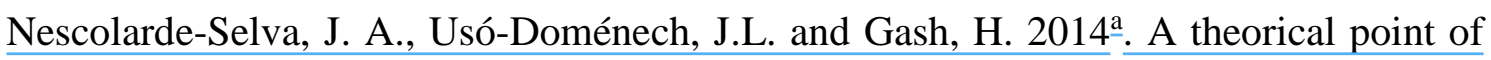
view of reality, perception, and language. Complexity. DOI: 10.1002/cplx.21493. 
Nescolarde-Selva, J. A., Usó-Doménech, J.L. and Gash, H. 2014르. A logic-mathematic point of view of reality, perception, and language. Complexity. DOI: 10.1002/cplx.21514

Nescolarde-Selva, J.A., Usó-Doménech J.L. and Sabán, M. 2014. Linguistic Knowledge of Reality: A Metaphysical Impossibility?. Foundations of Science. DOI: 10.1007/s10699-014-9347-1.

Peirce, C. S. 1958. Collected Papers of Charles Sanders Peirce, vols. 1-8, C. Hartshorne, P. Weiss y A. W. Burks (eds.). Cambridge, MA: Harvard University Press.

Schmidt, S. 1982. Foundations for the empirical study of literature (trans. and ed. R. de Beaugrande). Hamburg: Helmut Buske Verlag.

Samsonovich, A., V., Goldin, R., F. Ascoli, G., A. 2009. Toward a Semantic General Theory of Everything. Complexity. Vol(15), No 4. pp: 12-18.

Shklovsky, V. 1965. Art as technique. In L. T. Lemon \& M.J. Reis (Eds.and Trans.), Russian formalist criticism: Four essays. Lincoln, NE: University of Nebraska Press. (Original work published 1917.)

Spencer, H. 1872. Philosophy of style. New York: D. Appleton and Co.

Usó-Domènech, J.L., Vives-Maciá, F., Nescolarde Selva, J. and Patten, B.C. A Walford 's metadynamic point of view of ecosustainability ideology (I). INTERSYMP. 2009a .

Usó-Domènech, J.L., Vives-Maciá, F., Nescolarde Selva, J. and Patten, B.C. A Walford 's metadynamic point of view of ecosustainability ideology (II). INTERSYMP. 2009 $\stackrel{\text { b }}{\text {. }}$

Usó-Doménech, Nescolarde-Selva, J. 2012. Mathematic and semiotic theory of ideological systems. Editorial LAP. Sarrebruck. Germany.

Usó-Doménech, J. L. and Nescolarde-Selva, J. 2013. An introduction to Alysidal Algebra IV. Kybernetes. Vol. 42 (8). pp. 1235 - 1247.

Van Benthem, J.2012. The logic of empirical theories revisited. Synthese. 186, 775792.

van Peer, W. 1986. Stylistics and psychology: Investigations of foregrounding. London: Croom Helm.

van Dijk, T. A. 1979. Cognitive processing of literary discourse. Poetics Today, 1, 143159.

Willard, S. 2004.General Topology. Dover Publications. 